\title{
A New Strategy for Linkage Analysis under Epistasis Taking into Account Genetic Heterogeneity
}

\author{
Alexandre Bureau $^{a, b} \quad$ Chantal Mérette ${ }^{a, c} \quad$ Jordie Croteau ${ }^{a} \quad$ Alain Fournier $^{a}$ \\ Yvon C. Chagnon ${ }^{a, c}$ Marc-André Roy ${ }^{a, c}$ Michel Maziade ${ }^{a, c}$ \\ ${ }^{a}$ Centre de recherche, Université Laval Robert-Giffard; ${ }^{b}$ Département de médecine sociale et préventive and \\ 'Département de psychiatrie, Université Laval, Québec, Qué., Canada
}

\section{Key Words}

Bipolar disorder $\cdot$ Epistasis · Genetic heterogeneity $\cdot$

Parametric linkage analysis • Pedigree analysis •

Schizophrenia

\begin{abstract}
Background/Aims: Epistasis, the biological interaction of multiple genes modulating their individual effects, is likely omnipresent in complex diseases, and modelling epistasis in linkage studies can help detect loci with little marginal effect and detect epistatic effects themselves. We propose a complete three-step strategy for parametric linkage analysis under epistasis and heterogeneity in extended pedigrees. Methods: (1) Loci most likely involved in epistatic interactions are pre-screened using two-locus one-marker analyses. (2) Among selected loci, linkage to each locus is evaluated conditionally on linkage information at another locus under two-locus epistatic models. Linkage statistics are maximized over a space of epistatic models to avoid misspecification of model parameters. (3) Families linked to the conditioning locus are selected to deal with heterogeneity between pairs of epistatically interacting loci and other unlinked loci. Properties of conditional linkage statistics prevent the introduction of bias. Results: Simulations reveal important gains in power to detect a locus with weak marginal effect involved in epistatic interaction. Application of our
\end{abstract}

methods to schizophrenia and bipolar disorder in Eastern Quebec kindreds suggests epistasis between three locus pairs for bipolar disorder: 8p11-16p13, 15q11-16p13 and 18q12-15q11. Conclusion: These results suggest that the proposed strategy is powerful for tackling complex phenotypes involving epistasis and heterogeneity.

Copyright $\odot 2009$ S. Karger AG, Basel

\section{Introduction}

Biochemical interactions between the protein products of multiple genes are designated by the generic term of epistasis [1]. Epistasis implies that the onset of a disease is the result of a combination of genotypes in multiple genes, and it is expected to be widespread in the etiology of complex diseases [2].

With respect to disease penetrances of genotypes in populations, epistasis has been defined as any penetrance model which does not fit a definition of heterogeneity where two or more genes are independent causes of disease $[1,3,4]$. However, biological epistasis makes a significant contribution to disease risk only when genotypes containing disease susceptibility (DS) alleles at all loci in an epistatic system have much higher penetrances than the other genotypes. From this principle, we can derive narrower epistatic model spaces useful to achieve the two

\section{KARGER}

Fax +41613061234 E-Mail karger@karger.ch www.karger.com
(C) 2009 S. Karger AG, Basel

0001-5652/09/0684-0231\$26.00/0

Accessible online at:

www.karger.com/hhe
Alexandre Bureau

Médecine sociale et préventive, Pavillon de l'Est - local 1101, Université Laval

Québec, Qué. G1K 7P4 (Canada)

Tel. +1 418656 2131, ext. 3342, Fax +1 4186567759

E-Mail Alexandre.Bureau@msp.ulaval.ca 
main goals for modelling epistasis in genetic studies: to help detect disease loci showing little signal in analyses one locus at a time, and to suggest the presence of biological epistasis between previously detected loci.

Patterns of segregation in families are informative for epistasis. Under epistasis, carriers of DS alleles at one locus in the system but not at the others tend to be unaffected, even if they have affected offspring and affected parents or siblings. It takes extended pedigrees to identify these unaffected subjects appearing as obligate carriers of DS alleles, and it takes a genetic linkage analysis under epistatic models, allowing a clearer assignment of their genotype at the disease loci from their phenotype, to extract information from these unaffected subjects [5]. In the study of epistasis, linkage analysis therefore remains an important tool, complementary to association analysis which detects epistasis from genotype-specific disease risk.

Considerable work has been done on epistatic models in affected-only designs in small families such as affected sib-pairs (ASP) [6-11]. However, when epistasis follows a multiplicative model [3], such designs provide no gain, because the two-locus logarithm of odds (LOD) score is the sum of the one-locus LOD scores at the two loci when only affected subjects are considered. Even when epistasis does not fit multiplicative penetrance terms, in ASPs the two-locus interaction terms capturing departure from the multiplicative model are bounded by the marginal effects of each locus involved, and using two-locus linkage analysis provides little power gain over one-locus analysis [12].

Currently, the joint analysis of all pedigree members, both affected and unaffected, is only possible with parametric methods, nonparametric methods being designed for affected subjects only, or limited to discordant pairs. The earliest two-locus two-marker parametric analyses were undertaken in the 1990s with a few models and markers, due to limitations in the software and computing power available $[13,14]$ and did not address the challenge of two-locus model specification. At the time, an evaluation of multi-locus models via simulation found little gains in signal to detect epistatic loci using correctly specified epistatic models [15], but the focus on nuclear families as opposed to extended pedigrees appears to explain this result [5]. The computational demand of twolocus analyses, limiting pedigree size and the number of markers and models, and the lack of options to allow for heterogeneity with additional genes beyond the simple mixture model of Smith [16], have since discouraged the use of epistatic models in parametric linkage.
The development of optimized software [reviewed in 5] and the rapid increase in computer speed and memory in recent years have made parametric two-locus analysis much more computationally accessible. Maximizing the LOD score over genetic models, an enhancement to parametric linkage analysis that avoids the danger of model misspecification and has proved powerful in the onelocus setting $[17,18]$, can now be considered in the twolocus setting. In this paper we introduce LOD scores maximized over a space of epistatic models. We also take advantage of statistical properties of likelihoods for nested models to address the issue of heterogeneity with additional genes by exploiting information on linkage of individual families to the two epistatic genes, avoiding fitting an explicit heterogeneity model. These innovations were integrated into a complete three-step strategy for linkage analysis under epistasis and heterogeneity that consists of (1) pre-selection of candidate loci, (2) computation of sliced or conditional LOD scores, and (3) selection of families linked to the conditioning marker to address heterogeneity. The evaluation of the strategy by simulation revealed important power gains to detect a locus with weak marginal effect involved in an epistatic interaction. The strategy was then applied to a study of schizophrenia and bipolar disorder kindreds from Eastern Quebec $[19,20]$ and suggested epistasis between three locus pairs for bipolar disorder: 8p11-16p13, 15q11-16p13 and $18 \mathrm{q} 12-15 \mathrm{q} 11$.

\section{Methods}

Definition of Epistatic Model Space and Notation

We define a two-locus epistatic model space where the genotypes are divided into two groups, susceptible and nonsusceptible, and susceptible genotypes include DS alleles A at both loci. Each locus is dominant or recessive depending whether one or two copies of the DS allele are required in a susceptible genotype. The disease penetrance function of the model space is given by

$$
\begin{aligned}
& F\left(G_{D 1}, G_{D 2}\right)=\beta_{0}+\left(\delta_{1} I\left[G_{D 1}=\mathrm{A} / \mathrm{a}\right]+I\left[G_{D 1}=\mathrm{A} / \mathrm{A}\right]\right) \\
& \times\left(\delta_{2} I\left[G_{D 2}=\mathrm{A} / \mathrm{a}\right]+I\left[G_{D 2}=\mathrm{A} / \mathrm{A}\right]\right) \beta_{1}
\end{aligned}
$$

where a denotes a low risk allele, $G_{D j}$ is the genotype at the $j$-th locus which can be $\mathrm{a} / \mathrm{a}, \mathrm{A} / \mathrm{a}$ or $\mathrm{A} / \mathrm{A}, \delta_{\mathrm{j}}$ is the degree of dominance of allele $A$ at the $j$-th locus, taking value 0 for a recessive locus and 1 for a dominant locus, and $\mathrm{I}[\mathrm{C}]$ is an indicator function taking value 1 if the condition $C$ is satisfied and 0 otherwise. Expression (1) means that the disease penetrance equals $\beta_{0}$ for nonsusceptible genotypes and $\beta_{0}+\beta_{1}$ for susceptible genotypes, with $\beta_{0}$, $\beta_{1} \geq 0$ and $\beta_{0}+\beta_{1} \leq 1$. A similar model space was previously considered by MacLean et al. [15]. Table 1 gives an example of the penetrance matrix for a dominant-dominant model. In our model space, only the models where $\beta_{0}=0$ are multiplicative [3]. When 


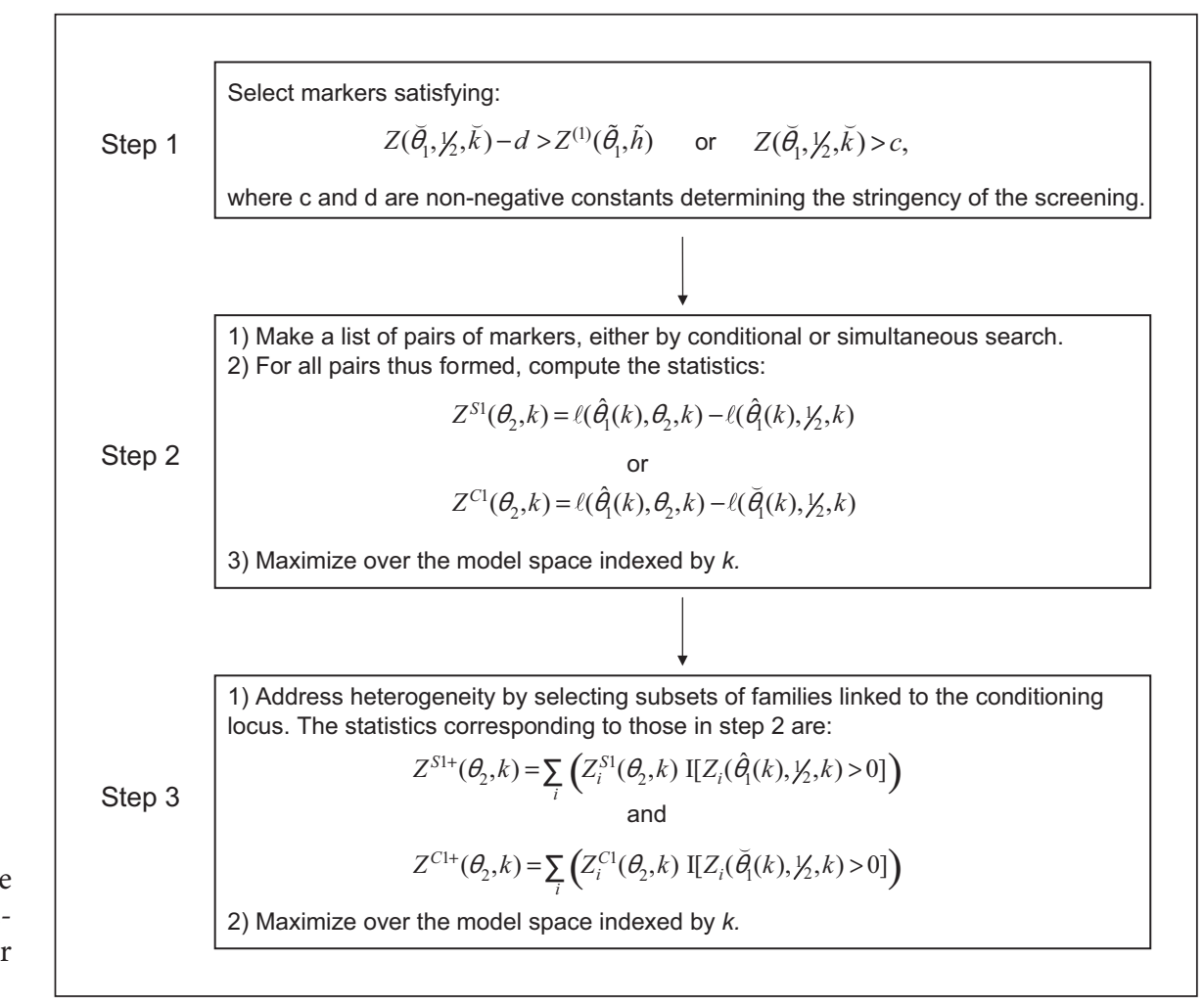

Fig. 1. Steps of the strategy for linkage analysis under epistasis taking into account genetic heterogeneity. See text for definition of the notation.

Table 1. Penetrance matrix for a dominant-dominant epistatic two-locus model ${ }^{\mathrm{a}}$

\begin{tabular}{|c|c|c|c|}
\hline \multirow[t]{2}{*}{$\mathrm{G}_{\mathrm{D} 1}$} & \multicolumn{3}{|c|}{$\mathrm{G}_{\mathrm{D} 2}$} \\
\hline & $a / a$ & $\mathrm{~A} / \mathrm{a}$ & $\mathrm{A} / \mathrm{A}$ \\
\hline $\mathrm{a} / \mathrm{a}$ & $\beta_{0}$ & $\beta_{0}$ & $\beta_{0}$ \\
\hline $\mathrm{A} / \mathrm{a}$ & $\beta_{0}$ & $\beta_{0}+\beta_{1}$ & $\beta_{0}+\beta_{1}$ \\
\hline $\mathrm{A} / \mathrm{A}$ & $\beta_{0}$ & $\beta_{0}+\beta_{1}$ & $\beta_{0}+\beta_{1}$ \\
\hline
\end{tabular}

a See Methods for definition of the symbols.

$\beta_{0}$ and $\beta_{1}$ are small, an unaffected phenotype provides little information on genotype probabilities, approximating an affectedonly analysis.

Under the assumptions of Hardy-Weinberg and linkage equilibrium between the two disease loci, the genotype frequencies are determined from the frequencies of the DS alleles at the two loci, $\mathrm{p}_{1}$ and $\mathrm{p}_{2}$. The prevalence $\pi$ of the disease in an unselected population is given by

$$
\pi=\beta_{0}+\mathrm{P}_{\mathrm{S}}\left(\mathrm{p}_{1}, \mathrm{p}_{2}, \delta_{1}, \delta_{2}\right) \beta_{1},
$$

where $\mathrm{P}_{\mathrm{S}}\left(\mathrm{p}_{1}, \mathrm{p}_{2}, \delta_{1}, \delta_{2}\right)$ is the prevalence of the group of susceptible genotypes. For a dominant-dominant model, $\mathrm{P}_{\mathrm{S}}\left(\mathrm{p}_{1}, \mathrm{p}_{2}, 1,1\right)=$ $\left(1-\left(1-p_{1}\right)^{2}\right)\left(1-\left(1-p_{2}\right)^{2}\right)$. We impose the constraint that $\pi$ equals a prespecified value under all models, usually an external estimate of the disease prevalence. For a set of values for $\beta_{0}, \beta_{1}, \delta_{1}, \delta_{2}$, $\mathrm{p}_{1}$ and $\pi$, we solve for $\mathrm{p}_{2}$. In this work, we considered values of 0 and 0.005 for $\beta_{0}$ and a range from 0.1 to 0.99 for $\beta_{1}$. For $p_{1}$, we considered a range from 0.01 to 0.1 for dominant loci and from 0.1 to 0.5 for recessive loci.

For a given mode of inheritance for each locus, let $\mathrm{k}=$ $\left(\beta_{0}, \beta_{1}, p_{1}, p_{2}, \delta_{1}, \delta_{2}\right)$ denote the parameters in a two-locus epistatic model and $\mathrm{h}=\left(\beta_{0}, \beta_{1}, \mathrm{p}_{1}, \delta_{1}\right)$, those for a one-locus model. While $\mathrm{k}$ and $\mathrm{h}$ could be seen as vectors of continuous parameters, in practice they index a finite grid of values of the parameter vector. For a pair of unlinked markers, we note the $\log _{10}$-likelihood for all families under the two-locus epistatic model $\mathrm{k}$ by $\left(\theta_{1}, \theta_{2}, \mathrm{k}\right)$, where $\theta_{j}$ represents the recombination fraction between the $\mathrm{j}$-th marker and the $\mathrm{j}$-th disease locus. The $\log _{10}$-likelihood for all families under the one-locus model $h$ at the $j$-th marker is noted $l^{(j)}\left(\theta_{j}, h\right)$. Affected as well as unaffected pedigree members contribute to the phenotypic and genotypic data unless otherwise specified.

\section{Strategy for Linkage Analysis under Epistasis Taking into}

Account Genetic Heterogeneity

The steps of the proposed strategy are presented schematically in figure 1 .

Step 1: Pre-Selection of Candidate Loci

We propose to identify pairs of candidate loci on which to perform the computer intensive two-locus two-marker analyses by 
detecting the loci most likely to be involved in epistasis in an initial screening stage. The approach can be applied to markers across the entire genome to detect loci where the one-locus signal is weakened by epistasis and heterogeneity, or across regions where linkage has previously been detected using one-locus approaches, to seek improvements in signal suggesting the presence of epistasis. When there is epistasis, the linkage signal under the best fitting two-locus epistatic model is expected to exceed the signal under the best fitting marginal one-locus model, because the epistatic model captures the disease transmission pattern better [5]. The screening stage selects markers based on that principle. For each marker, the following tasks are performed: (1) compute the two-locus, one marker LOD score under each two-locus epistatic model $\mathrm{k}$, defined as

$$
Z\left(\theta_{1}, 1 / 2, \mathrm{k}\right)=\ell\left(\theta_{1}, 1 / 2, \mathrm{k}\right)-\ell(1 / 2,1 / 2, \mathrm{k})[21]
$$

and the LOD score under the one-locus model h defined as

$$
Z^{(1)}\left(\theta_{1}, h\right)=\ell^{(1)}\left(\theta_{1}, h\right)-\ell^{(1)}(1 / 2, h) .
$$

(2) Maximize $\mathrm{Z}\left(\theta_{1}, 1 / 2, \mathrm{k}\right)$ over $\theta_{1}$ and $\mathrm{k}$ and maximize $\mathrm{Z}^{(1)}\left(\theta_{1}, \mathrm{~h}\right)$ over $\theta_{1}$ and $\mathrm{h}$, both subject to the constraint that the prevalence equals the prespecified value $\pi$, to obtain $Z\left(\breve{\theta}_{1}, 1 / 2, \breve{k}\right)$ and $Z^{(1)}\left(\tilde{\theta}_{1}\right.$, $\tilde{\mathrm{h}})$, where $\tilde{\theta}_{1}$ and $\breve{\mathrm{k}}$ are the recombination fraction and epistatic model maximizing $\mathrm{Z}\left(\theta_{1}, 1 / 2, \mathrm{k}\right)$ and $\tilde{\theta}_{1}$ and $\tilde{\mathrm{h}}$ are the recombination fraction and one-locus model maximizing $\mathrm{Z}_{(1)}\left(\theta_{1}, \mathrm{~h}\right)$. (3) Select markers satisfying

$$
\mathrm{Z}\left(\breve{\theta}_{1} 11 / 2, \breve{\mathrm{k}}\right)-\mathrm{d}>\mathrm{Z}^{(1)}\left(\tilde{\theta}_{1}, \tilde{\mathrm{h}}\right)
$$

or

$$
\mathrm{Z}\left(\breve{\theta}_{1}, 1 / 2, \breve{\mathrm{k}}\right)>\mathrm{c},
$$

where $\mathrm{c}$ and $\mathrm{d}$ are non-negative constants determining the stringency of the screening. We refer to inequalities (2) and (3) as the Step 1 criteria. Inequality (3) is introduced because the stronger locus in an epistatic pair of loci can show a strong marginal effect, and in that case $Z\left(\breve{\theta}_{1}, 1 / 2, \breve{k}\right)$ may not exceed $Z^{(1)}\left(\tilde{\theta}_{1}, \tilde{h}\right)$. Since heterogeneity with other loci may attenuate LOD scores such as $\mathrm{Z}^{(1)}\left(\theta_{1}, \mathrm{~h}\right)$ and $\mathrm{Z}\left(\theta_{1}, 1 / 2, \mathrm{k}\right)$, heterogeneity LOD (HLOD) scores computed from the individual family values of these two scores under the mixture model proposed by Smith [16] can be used as an alternative. The purpose of this screening stage being to reduce the computational burden, the values of $\mathrm{c}$ and $\mathrm{d}$ are dictated by the amount of computing possible at the following steps. For c, we suggest using the threshold for suggestive linkage. Either inequality can be omitted by setting $\mathrm{c}$ or $\mathrm{d}$ to infinity.

Step 2: Computation of Sliced and Conditional LOD Scores

The second step involves the joint linkage analysis of two preselected markers, each one assumed to be linked to one of the loci of an epistatic two-locus model. The evidence for linkage of both markers to their respective disease locus is measured by the twolocus two-marker LOD score:

$$
\mathrm{Z}\left(\theta_{1}, \theta_{2}, \mathrm{k}\right)=\ell\left(\theta_{1}, \theta_{2}, \mathrm{k}\right)-\ell(1 / 2,1 / 2, \mathrm{k})[13]
$$

which is maximized at $\left(\hat{\theta}_{1}(\mathrm{k}), \hat{\theta}_{2}(\mathrm{k})\right)$ under model $\mathrm{k}$.

Interpreting the statistical significance of this statistic remains difficult, however $[5,13]$. A more natural way to measure the impact of modelling epistasis is the improvement in linkage signal to one of the markers compared to a one-locus analysis. The linkage signal at a locus under a two-locus model is assessed by conditioning on the linkage information at the other locus in the model $[13,15]$. Depending on context, one may wish to condition only on previously detected loci (conditional search [22]) or, for each marker, to condition on every other (simultaneous search [22]).

Conditioning on locus 1 implies subtracting $\ell\left(\theta_{1}, 1 / 2, \mathrm{k}\right)$ from $\ell\left(\theta_{1}, \theta_{2}, \mathrm{k}\right)$. The exact position of the conditioning locus being unknown, one has to substitute an estimate of $\theta_{1}$ in the two log-likelihoods. One approach adopted by many authors [6, 7, 13, 23, 24], is to set $\theta_{1}$ (or equivalently the position of locus 1 on a marker map) to its two-marker analysis maximum LOD score estimate $\hat{\theta}_{1}(\mathrm{k})$ in both log-likelihoods to obtain the 'sliced' LOD score:

$$
Z^{S 1}\left(\theta_{2}, k\right)=\ell\left(\hat{\theta}_{1}(k), \theta_{2}, k\right)-\ell\left(\hat{\theta}_{1}(k), 1 / 2, k\right)
$$

As an alternative, we propose to set $\theta_{1}$ in $\ell\left(\theta_{1}, 1 / 2, \mathrm{k}\right)$ to the value $\breve{\theta}_{1}(\mathrm{k})$ maximizing $\mathrm{Z}\left(\theta_{1}, 1 / 2, \mathrm{k}\right)$, to obtain what we call the conditional LOD score:

$$
Z^{\mathrm{Cl}}\left(\theta_{2}, k\right)=\ell\left(\hat{\theta}_{1}(k), \theta_{2}, k\right)-\ell\left(\check{\theta}_{1}(k), 1 / 2, k\right)
$$

Estimating $\theta_{1}$ from LOD scores conditional on the phenotype prevents bias due to ascertainment in $\mathrm{Z}^{\mathrm{S1}}\left(\theta_{2}, \mathrm{k}\right), \mathrm{Z}^{\mathrm{Cl}}\left(\theta_{2}, \mathrm{k}\right)$ or the estimates of $\theta_{2}$ obtained from them.

For a fixed two-locus model $\mathrm{k}, \mathrm{Z}^{\mathrm{Cl}}\left(\theta_{2}, \mathrm{k}\right)$ maximized with respect to $\theta_{2}, Z^{\mathrm{Cl}}\left(\hat{\theta}_{2}(\mathrm{k}), \mathrm{k}\right)$, is a likelihood ratio (LR) statistic comparing the general model with $\left(\theta_{1}, \theta_{2}\right)$ free to the restricted model with $\theta_{1}$ free and $\theta_{2}=1 / 2$. When the restricted model is true, the asymptotic distribution of a LR statistic is $\chi^{2}$ [25, pp 151-160]. In the present case, the asymptotic distribution of $\mathrm{Z}^{\mathrm{Cl}}\left(\hat{\theta}_{2}(\mathrm{k}), \mathrm{k}\right)$ multiplied by $2 \log 10$ is a mixture of a $\chi^{2}{ }_{(1)}$ distribution and a point mass at 0 , because of the one-sided alternative $\theta_{2}<1 / 2$. The distribution of $Z^{\mathrm{S} 1}\left(\hat{\theta}_{2}(\mathrm{k}), \mathrm{k}\right)$ has not been studied analytically to our knowledge.

As for other LOD scores, $\mathrm{Z}^{\mathrm{Cl}}\left(\theta_{2}(\mathrm{k}), \mathrm{k}\right)$ and $\mathrm{Z}^{\mathrm{S1}}\left(\theta_{2}, \mathrm{k}\right)$ can be further maximized with respect to the genetic model space indexed by $\mathrm{k}$. The need to estimate the recombination fraction $\theta_{1}$ with the conditioning locus leads us to perform the maximization in two steps: first, maximizing with respect to $\theta_{1}$ and $\theta_{2}$ for each model $\mathrm{k}$ in the predetermined set of epistatic models and second, maximizing over the set of models indexed by $\mathrm{k}$.

Step 3: Selection of Families Linked to the Conditioning Marker to Address Heterogeneity

Only a fraction of the families in a sample may be linked to a pair of epistatic loci because of genetic heterogeneity. While mixture models can be applied in the context of two-locus analysis [26], conditioning on the linkage information at one locus in the pair affords a more powerful alternative: selecting families showing evidence for linkage to the conditioning locus. Considering that the $\mathrm{i}$-th family is linked to the conditioning locus if the family LOD score $Z_{i}\left(\check{\theta}_{1}(k), 1 / 2, k\right)>0$, we define the conditional LOD score at the second locus in families linked to the conditioning locus as:

$$
Z^{C 1+}\left(\theta_{2}, k\right)=\sum_{i}\left(Z_{i}^{C 1}\left(\theta_{2}, k\right) \mathrm{I}\left[Z_{i}\left(\breve{\theta}_{1}(k), 1 / 2, k\right)>0\right]\right)
$$

and the corresponding sliced LOD score as:

$$
Z^{S 1+}\left(\theta_{2}, k\right)=\sum_{i}\left(Z_{i}^{S 1}\left(\theta_{2}, k\right) \mathrm{I}\left[Z_{i}\left(\hat{\theta}_{1}(k), 1 / 2, k\right)>0\right]\right)
$$


This approach extends to parametric linkage analysis under twolocus models the idea of Cox et al. [27] to sum the second locus nonparametric (one-locus) LOD score [28] of the families with a positive nonparametric linkage (NPL) score [29] at the conditioning locus. Cox et al.'s [27] approach detects pairs of loci where families tend to be linked to both loci or to neither of the two, a pattern expected in presence of epistasis between the two loci and heterogeneity with other loci [15]. However, that approach still models the genotype-phenotype relationship one locus at a time. Our approach adds the modeling of the genotype at two loci simultaneously. Parametric LOD scores analogous to Cox et al.'s nonparametric LOD score can be defined using the one-locus LOD score summed over the same set of families as for the conditional and sliced LOD scores. For comparison to the conditional LOD score, the statistic is:

$$
Z^{(2) C 1+}\left(\theta_{2}, k, h\right)=\sum_{i}\left(Z_{i}^{(2)}\left(\theta_{2}, h\right) \mathrm{I}\left[Z_{i}\left(\breve{\theta}_{1}(k), 1 / 2, k\right)>0\right]\right)
$$

The asymptotic $\chi^{2}$ distribution of a LR statistic between two nested models when the restricted model is true does not depend on the likelihood under the restricted model. This implies that the asymptotic distribution of $Z^{\mathrm{Cl}}\left(\hat{\theta}_{2}(\mathrm{k}), \mathrm{k}\right)$ under the null hypothesis $\theta_{2}=1 / 2$ does not depend on $\ell\left(\breve{\theta}_{1}(k), 1 / 2, k\right)$, or the individual family likelihood $\ell_{i}\left(\breve{\theta}_{1}(k), 1 / 2, k\right)$. Therefore, one can specify a weighting scheme for $\mathrm{Z}_{i}^{\mathrm{Cl}}\left(\hat{\theta}_{2}(\mathrm{k}), \mathrm{k}\right)$ which depends on $\ell_{i}\left(\vec{\theta}_{1}(k), 1 / 2, k\right)$ (here giving weight 1 to the families with $Z_{i}\left(\breve{\theta}_{1}(k), 1 / 2, k\right)>0$ and weight 0 to the others) without altering the asymptotic null distribution of the sum, i.e. $\mathrm{Z}^{\mathrm{Cl}+}\left(\hat{\theta}_{2}(\mathrm{k}), \mathrm{k}\right)$ has the same null distribution as a usual LOD score.

$\mathrm{Z}^{\mathrm{Cl}+}\left(\hat{\theta}_{2}(\mathrm{k}), \mathrm{k}\right)$ and $\mathrm{Z}^{\mathrm{S} 1+}\left(\hat{\theta}_{2}(\mathrm{k}), \mathrm{k}\right)$ can be further maximized with respect to the genetic model space. One can also evaluate the statistics $\mathrm{Z}^{(2) \mathrm{Cl}+}$ and $\mathrm{Z}^{(2) \mathrm{S1}+}$ at the models maximizing, respectively, $\mathrm{Z}^{\mathrm{Cl}+}$ and $\mathrm{Z}^{\mathrm{Sl}+}$ for comparison purposes, and further maximize these statistics over one-locus models.

\section{Simulation of the Null Distribution of Statistics Maximized} over a Genetic Model Space

In arbitrary pedigrees, the theoretical null distribution of onelocus LOD scores maximized over the genetic model is not known and computer simulations must be performed to approximate it [30]. Further, the distribution of the maximized LOD score depends on pedigree size and structure, and it is therefore preferable to perform simulations using the structures of the families from the sample at hand rather than to rely on a generic null distribution [30]. We apply this recommendation in the two-locus setting. Two important issues need to be considered when performing these simulations, in relation to the analysis strategy proposed in this paper.

The first is the definition of the null hypothesis for conditional and sliced LOD scores: that the tested marker is unlinked to any disease gene $\left(\theta_{2}=1 / 2\right)$ given the linkage information at the conditioning locus. This null hypothesis does not specify the recombination fraction of the marker at the conditioning locus, a locus usually showing evidence for linkage, i.e. $\theta_{1}<1 / 2$. Simulations of the null distribution of conditional LOD scores should therefore incorporate linkage evidence to the conditioning locus [7]. In actual data sets, the natural way to do this is to keep the original genotypes of the conditioning marker (and the original phenotypes) in all simulated replicates of the family sample. A generic unlinked marker can be simulated as the tested marker. While ideally this should be repeated for every conditioning marker, the null distribution simulated with one conditioning marker can be reused to assess significance of LOD scores conditioned on other markers to save on computations.

The second issue is the computational burden of analyzing thousands of simulated datasets with two markers under two-locus models. With current processors, this can only be performed within a reasonable amount of computing time for moderate sized pedigrees. Our proposed strategy however only requires to perform the two-locus two-marker likelihood computations when the Step 1 criteria (2) and (3) are met. In the simulations under the null, this implies that analyzing only the replicates satisfying Step 1 criteria is sufficient to obtain a null distribution of the conditional and sliced LOD scores reflecting the analysis strategy.

\section{Software}

We used Superlink $[31,32]$ to perform linkage computations, the only currently available program capable of executing twolocus two-marker computations in large pedigrees. We wrote scripts in Perl and the S language for the R environment to set up Superlink input files for the analysis of marker pairs under a set of two-locus epistatic models, and to process output files. These scripts are available upon request.

\section{Simulation Study}

\section{Simulation Study Setup}

We simulated three-generation pedigrees composed of three nuclear families, each with four offspring, as illustrated in figure 2 . The epistatic model used in the simulations involved two dominant genes on two distinct chromosomes. Susceptible genotypes were necessary to be affected $\left(\beta_{0}=0\right)$ and had high penetrance $\left(\beta_{1}=0.89\right)$. DS allele frequencies were chosen to obtain a disease prevalence $\pi=0.01$. Frequencies of 0.03 for gene 1 and 0.1 for gene 2 resulted in a strong one-locus linkage signal at gene 1 and a weak signal at gene 2 , allowing us to evaluate the ability of our approach to detect gene 2 . In simulations under homogeneity, this model was applied to generate all families. In simulations under heterogeneity, this model was applied to generate half the families, the other half being generated under a one-locus strict dominant model with penetrance of 0.7 , that is $\beta_{1}=0.7$ and $\beta_{0}=0$, and DS allele frequency of 0.0072 . We also performed simulations with two dominant genes on distinct chromosomes under one definition of a heterogeneity model [15], where carriers of a disease allele in at least one of the genes had penetrance of 0.7 and non-carriers could not be affected.

Our ascertainment criterion required at least one affected cousin pair. In some analyses, we further required that at least one of the two pivot individuals was unaf- 


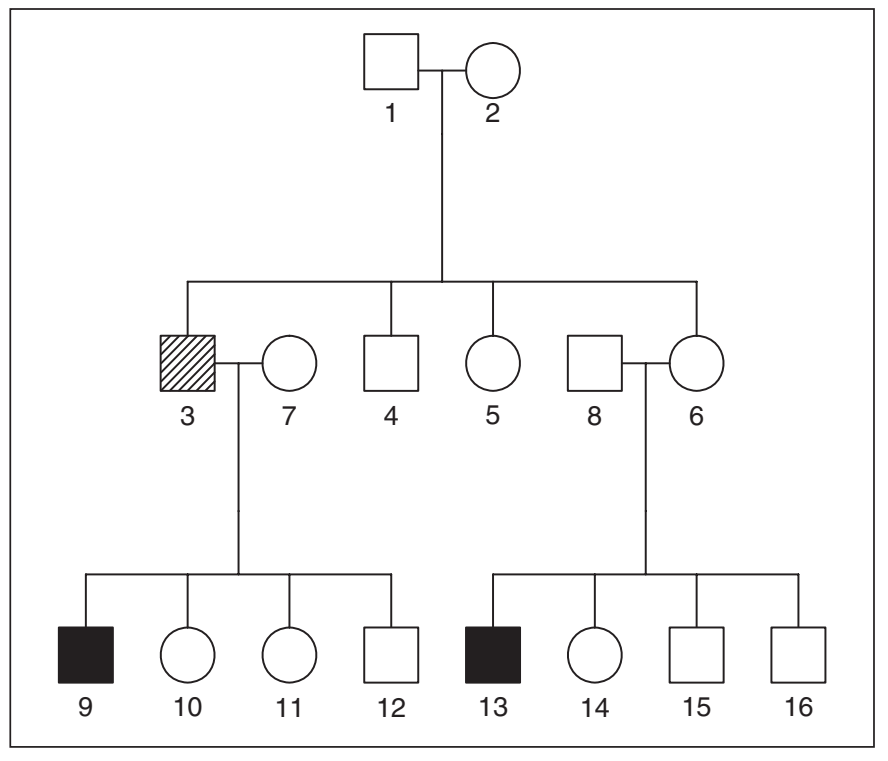

Fig. 2. Pedigree structure used in the simulation study. Subject 3 with diagonal line pattern was necessarily unaffected in some simulations; black filled symbols represent the subjects who were necessarily affected; subjects with an empty symbol could be either affected or unaffected.

fected (subject 3 in fig. 2), appearing as an obligate carrier. We imposed this condition to mimic our actual schizophrenia and bipolar disorder families, where we observed obligate carriers in $67 \%$ of families. Without the selection criterion on the pivots, both the epistatic model and the one-gene model with reduced penetrance resulted in at least one unaffected pivot in about $53 \%$ of families.

We simulated markers with four equifrequent alleles, resulting in heterozygosity of $75 \%$. Markers were placed at $5 \mathrm{cM}$ intervals, with one marker on top of the disease locus on each chromosome. All phenotype and marker genotype data were simulated using the computer package Simla [33].

In addition to simulations with both markers linked to disease loci, we also simulated 19,000 replicates of 10 families under the null hypothesis where the tested marker is unlinked $\left(\theta_{2}=1 / 2\right)$. For these simulations, the disease phenotype was simulated under the one-locus strict dominant model described above.

\section{Simulation Results}

The estimated quantiles of the null distribution of the statistics considered in this paper are presented in table 2 . For a fixed genetic model, the quantiles of the distribu- tion of the statistics are close to those from the theoretical $\chi^{2}$ distribution. Maximization over the models shifted the distributions to the right: at the significance level of 0.0017 recommended for suggestive linkage in a genome scan [34], the quantile is inflated by 0.7 to 1.0 compared to using a fixed model.

These null distributions were used to compute the $\mathrm{p}$ values of the statistics in simulations with markers linked to two genes. All results reported here involve markers located on top of a disease gene. The signal decreased with the distance between the marker and the disease gene as expected (results not shown). Gene 1, with strong one-locus linkage signal, satisfied the Step 1 criteria (2) and (3), here with $c=2.68$ and $d=0$, in all replicates (results not shown).

Table 3 presents the linkage signals at gene 2, where the one-locus linkage signal is weak, in families with at least one unaffected pivot. For analyses conditioning on gene 1, power was calculated in two ways: (1) assuming that the analysis is performed irrespective of the one-locus linkage at gene 2, and (2) assuming that the analysis is performed only when the Step 1 criteria are satisfied (pre-select). With all families linked to the two epistatic genes (left-hand side of table 3), the LOD $\left(\mathrm{Z}^{\mathrm{Cl}}\right.$ and $\left.\mathrm{Z}^{\mathrm{S1}}\right)$ or $\mathrm{HLOD}\left(\mathrm{Z}^{\mathrm{HCl}}\right.$ and $\left.\mathrm{Z}^{\mathrm{HS1}}\right)$ versions of the Step 2 conditional and sliced analyses had increased power compared to the one-locus analysis, and they estimated $\theta_{2}$ on average closer to the true value of 0 . Since all families were actually linked, applying Step 3 and selecting families with a positive $Z_{\mathrm{i}}\left(\hat{\theta}_{1}(\mathrm{k}), 1 / 2, \mathrm{k}\right)$ ( $81 \%$ of all families) slightly reduced the power to detect gene 2 compared to using all families. The Step 1 criteria applied to LOD scores were satisfied in $90 \%$ of the replicates, and power remained about the same when analysis of gene 2 was limited to these replicates. The condition $Z\left(1 / 2, \breve{\theta}_{2}, \breve{k}\right)>Z^{(2)}\left(\tilde{\theta}_{2}, \tilde{h}\right)$ was the most often satisfied, in $81 \%$ of the replicates. By comparison, in simulations under our two-locus heterogeneity model, we observed $Z\left(1 / 2, \breve{\theta}_{2}, \breve{k}\right)>Z^{(2)}\left(\tilde{\theta}_{2}, \tilde{h}\right)$ in only $57 \%$ of replicates. Using the HLOD instead of the LOD for evaluating the Step 1 criteria resulted in a slightly lower power (results not shown).

The power of the Step 2 analyses was lower for simulations under heterogeneity between the two-gene epistatic system and a third gene elsewhere than under homogeneity, despite a fourfold increase in sample size (right-hand side of table 3). Families with a positive $\mathrm{Z}_{\mathrm{i}}\left(\hat{\theta}_{1}(\mathrm{k}), 1 / 2, \mathrm{k}\right)$ at the conditioning marker represented $56 \%$ of all families, $80 \%$ of truly linked families and $32 \%$ of unlinked families. Selection of families with a positive LOD score at gene 1 (Step 3) considerably increased the 
Table 2. Quantiles of null distribution of linkage statistics in simulated families (with $95 \%$ confidence intervals)

\begin{tabular}{|c|c|c|c|c|c|c|}
\hline \multirow[t]{2}{*}{ Statistic } & \multirow[t]{2}{*}{ Model } & \multicolumn{5}{|l|}{ Significance level } \\
\hline & & 0.05 & 0.01 & 0.005 & 0.0017 & 0.001 \\
\hline \multirow{3}{*}{$\begin{array}{l}\chi^{2}\left({ }^{a}\right)^{a} \\
Z\left(\breve{\theta}_{1}, 1 / 2\right)\end{array}$} & & 0.59 & 1.18 & 1.44 & 1.86 & 2.07 \\
\hline & fixed $^{b}$ & $0.58(0.56,0.60)$ & $1.16(1.10,1.21)$ & $1.39(1.34,1.48)$ & $1.70(1.63,1.77)$ & $1.86(1.71,2.14)$ \\
\hline & best $^{c}$ & $1.25(1.22,1.28)$ & $1.89(1.85,1.97)$ & $2.22(2.11,2.29)$ & $2.68(2.56,2.79)$ & $2.81(2.72,3.00)$ \\
\hline \multirow[t]{2}{*}{$\mathrm{Z}^{\mathrm{C} 1}$} & fixed $^{b}$ & $0.59(0.57,0.61)$ & $1.17(1.13,1.22)$ & $1.41(1.35,1.51)$ & $1.85(1.74,2.01)$ & $2.04(1.94,2.17)$ \\
\hline & best $^{c}$ & $1.29(1.27,1.31)$ & $1.96(1.90,2.02)$ & $2.23(2.16,2.29)$ & $2.69(2.51,2.92)$ & $3.06(2.73,3.24)$ \\
\hline \multirow[t]{2}{*}{$Z^{S 1}$} & fixed $^{b}$ & $0.59(0.57,0.61)$ & $1.18(1.13,1.22)$ & $1.41(1.35,1.51)$ & $1.85(1.74,2.00)$ & $2.04(1.94,2.17)$ \\
\hline & best $^{\mathrm{c}}$ & $1.29(1.27,1.33)$ & $1.96(1.90,2.02)$ & $2.23(2.17,2.33)$ & $2.69(2.51,2.95)$ & $3.06(2.73,3.24)$ \\
\hline \multirow[t]{2}{*}{$\mathrm{Z}^{\mathrm{Cl}+}$} & fixed $^{b}$ & $0.61(0.58,0.64)$ & $1.20(1.16,1.26)$ & $1.42(1.36,1.52)$ & $1.89(1.74,2.03)$ & $2.08(1.95,2.24)$ \\
\hline & best $^{c}$ & $1.36(1.33,1.39)$ & $2.04(1.99,2.09)$ & $2.31(2.23,2.38)$ & $2.76(2.60,2.91)$ & $2.92(2.81,3.14)$ \\
\hline \multirow[t]{2}{*}{$\mathrm{Z}^{\mathrm{S} 1+}$} & fixed $^{b}$ & $0.59(0.57,0.61)$ & $1.19(1.14,1.25)$ & $1.42(1.36,1.51)$ & $1.89(1.74,2.03)$ & $2.08(1.95,2.24)$ \\
\hline & best $^{c}$ & $1.32(1.29,1.35)$ & $2.01(1.94,2.07)$ & $2.27(2.19,2.34)$ & $2.72(2.59,2.89)$ & $2.92(2.79,3.14)$ \\
\hline
\end{tabular}

\footnotetext{
${ }^{\text {a }}$ Quantiles of the one-sided $\chi^{2}{ }_{(1)}$ distribution multiplied by $2 \log 10$.

${ }^{\mathrm{b}}$ LOD scores are obtained by fixing one dominant-dominant model, defined by the parameters $\mathrm{p}_{1}=0.01, \mathrm{p}_{2}=0.15, \beta_{0}=0.005$ and $\beta_{1}=0.9$.

${ }^{\mathrm{c}}$ LOD scores are maximized over the family of epistatic models considered in this paper with the disease prevalence set to $\pi=$ 0.01 .
}

Table 3. Signal at locus with weak marginal effect (locus 2), in families with an unaffected pivot

\begin{tabular}{|c|c|c|c|c|c|c|c|c|c|}
\hline & \multirow[t]{2}{*}{ Statistic $^{\mathrm{a}}$} & \multicolumn{4}{|c|}{$\begin{array}{l}\text { Two epistatic genes only } \\
\text { (100 replicate samples of } 10 \text { families) }\end{array}$} & \multicolumn{4}{|c|}{$\begin{array}{l}\text { Two epistatic genes plus heterogeneity } \\
\text { (100 replicate samples of } 40 \text { families) }\end{array}$} \\
\hline & & mean $\pm S D$ & $\begin{array}{l}\operatorname{mean} \theta \\
\pm \mathrm{SD}\end{array}$ & power $^{\mathrm{b}}$ & $\begin{array}{l}\text { power }^{\mathrm{b}} \\
\text { (pre-select) }\end{array}$ & mean $\pm S D$ & $\begin{array}{l}\text { mean } \theta \\
\pm S D\end{array}$ & power $^{b}$ & $\begin{array}{l}\text { power }^{\mathrm{b}} \\
\text { (pre-select) }\end{array}$ \\
\hline \multicolumn{10}{|l|}{ All families } \\
\hline \multirow[t]{2}{*}{ One-locus analyses } & $\operatorname{LOD}\left(Z^{(2)}\right)$ & $2.01 \pm 1.15$ & $0.14 \pm 0.10$ & 0.36 & NA & $1.41 \pm 1.07$ & $0.26 \pm 0.10$ & 0.13 & NA \\
\hline & $\operatorname{HLOD}\left(\mathrm{Z}^{\mathrm{H}(2)}\right)$ & $2.16 \pm 1.13$ & $0.10 \pm 0.10$ & 0.33 & NA & $1.97 \pm 1.12$ & $0.11 \pm 0.11$ & 0.25 & NA \\
\hline \multirow[t]{4}{*}{ Two-locus analyses } & Conditional LOD $\left(\mathrm{Z}^{\mathrm{C} 1}\right)$ & $3.54 \pm 1.43$ & $0.03 \pm 0.05$ & 0.65 & 0.63 & $2.64 \pm 1.42$ & $0.08 \pm 0.09$ & 0.42 & 0.42 \\
\hline & Sliced LOD $\left(\mathrm{Z}^{\mathrm{S1}}\right)$ & $3.59 \pm 1.44$ & $0.03 \pm 0.05$ & 0.65 & 0.63 & $2.66 \pm 1.42$ & $0.08 \pm 0.09$ & 0.42 & 0.42 \\
\hline & Conditional HLOD $\left(\mathrm{Z}^{\mathrm{HCl}}\right)$ & $3.61 \pm 1.42$ & $0.02 \pm 0.04$ & 0.63 & 0.63 & $3.13 \pm 1.49$ & $0.03 \pm 0.05$ & 0.53 & 0.54 \\
\hline & Sliced HLOD $\left(\mathrm{Z}^{\mathrm{HS} 1}\right)$ & $3.64 \pm 1.43$ & $0.02 \pm 0.04$ & 0.63 & 0.63 & $3.10 \pm 1.48$ & $0.03 \pm 0.05$ & 0.52 & 0.54 \\
\hline \multicolumn{10}{|l|}{ Selected families } \\
\hline \multirow[t]{2}{*}{ One-locus analyses } & Cox LOD $\left(\mathrm{Z}^{(2) \mathrm{C} 1+}\right)$ & $1.84 \pm 1.15$ & $0.12 \pm 0.09$ & 0.26 & NA & $1.89 \pm 1.34$ & $0.20 \pm 0.10$ & 0.26 & NA \\
\hline & Cox LOD $\left(Z^{(2) S 1+}\right)$ & $1.83 \pm 1.14$ & $0.12 \pm 0.09$ & 0.26 & NA & $1.99 \pm 1.31$ & $0.19 \pm 0.09$ & 0.28 & NA \\
\hline \multirow[t]{2}{*}{ Two-locus analyses } & Conditional LOD $\left(\mathrm{Z}^{\mathrm{Cl}+}\right)$ & $3.12 \pm 1.29$ & $0.02 \pm 0.04$ & 0.56 & 0.57 & $3.84 \pm 1.74$ & $0.07 \pm 0.08$ & 0.71 & 0.67 \\
\hline & Sliced LOD $\left(\mathrm{Z}^{\mathrm{S1+}}\right)$ & $3.05 \pm 1.31$ & $0.05 \pm 0.07$ & 0.54 & 0.54 & $3.41 \pm 1.57$ & $0.10 \pm 0.09$ & 0.64 & 0.61 \\
\hline
\end{tabular}

power of the conditional and sliced LOD scores, with the conditional LOD showing a greater gain and the highest power overall. The mean estimate of $\theta_{2}$ around 0.08 remained however similar with or without Step 3. In contrast, simply summing the one-locus LOD scores for gene 2 of the selected families $\left(\mathrm{Z}^{(2) \mathrm{Cl}+}\right.$ and $\left.\mathrm{Z}^{(2) \mathrm{S} 1+}\right)$, following the idea of Cox et al. [27], only provided a modest gain in power over the one-locus LOD score and low accuracy for estimating $\theta_{2}$. The power of the conditional and sliced HLOD $\mathrm{Z}^{\mathrm{HCl}}$ and $\mathrm{Z}^{\mathrm{HS1}}$ was higher than that of 
$\mathrm{Z}^{(2)}, \mathrm{Z}^{\mathrm{H}(2)}, \mathrm{Z}^{\mathrm{Cl}}, \mathrm{Z}^{\mathrm{S} 1}, \mathrm{Z}^{(2) \mathrm{Cl}+}$ and $\mathrm{Z}^{(2) \mathrm{S} 1+}$, but lower than the power of $Z^{\mathrm{Cl}+}$ and $\mathrm{Z}^{\mathrm{S1}+}$. $\mathrm{Z}^{\mathrm{HCl}}$ and $\mathrm{Z}^{\mathrm{HS1}}$ however provided the most accurate estimates of $\theta_{2}$. The Step 1 criteria were satisfied in $90 \%$ of the replicates, and again analyzing only these replicates little affected power. Substitution of the LOD by the HLOD to evaluate the Step 1 criteria led again to a slight power reduction (results not shown). All above observations also apply to simulations where families with two affected pivot individuals were included (see online supplementary table 1, www. karger.com/doi/10.1159/000228921).

In summary, we observed that applying Step 1 of our strategy to reduce the computational burden preserved the power to detect linkage to gene 2 in subsequent steps. Applying Step 3 was the most powerful approach in presence of heterogeneity, and incurred little loss of power when all families were homogeneously linked to the epistatic system. The conditional and sliced LOD scores were close to each other across simulation settings, with the conditional LOD score providing a slight power advantage after Step 3.

\section{Application to Schizophrenia and Bipolar Disorder}

Schizophrenia (SZ) and bipolar disorder (BP) are two major psychiatric disorders with a complex etiology. A model of epistatic interaction has been proposed to explain the familial aggregation pattern of SZ [3] and evidence of epistasis between loci has been reported for SZ [35] and BP [36]. Our analysis of an initial sample of 21 kindreds from Eastern Quebec containing SZ, BP and mixed SZ and BP families studied using homogeneous diagnostic and genotyping methods led to the detection of genome-wide significant or suggestive linkage signals in nine regions of the genome [19], some of which having been replicated in a second sample of 27 kindreds [20]. Here we investigate whether our strategy detects epistasis between pairs of markers from six of these regions (6p23-p22, 12q23, 13q13-q14, 15q11, 16p12-p13 and $18 \mathrm{q} 12-\mathrm{q} 21$ ), plus the SCZD6 locus on 8p, after accounting for heterogeneity with other loci in an expanded sample.

\section{Sample and Phenotype Description}

The full sample of 48 kindreds, with a total of 1,274 members, 378 of whom were affected by SZ or BP spectrum disorder $[19,20]$, was used in this analysis. A bestestimate lifetime DSM-IIIR or DSM-IV diagnosis was made with stringent procedures outlined in previous re- ports [37-39]. Ascertainment, diagnostic methods and genotyping procedures for microsatellite markers have also been described in detail elsewhere [19, 20, 37-39].

We used a narrow SZ definition restricted to SZ and a broad definition comprising SZ narrow plus schizophreniform disorder and schizotypal personality. The BP narrow phenotype was restricted to BP I and the broad definition included BP I, BP II, and recurrent major depression. We also defined a narrow and broad 'common locus' (CL) phenotype. The narrow CL phenotype included BP narrow, SZ narrow and schizoaffective disorder (SAD). The broad CL definition included the broad definitions of BP and SZ, in addition to SAD.

\section{Strategy for Analysis of Epistasis}

We followed the three steps of the proposed analysis strategy. In Step $1, Z\left(\breve{\theta}_{1}, 1 / 2, \breve{k}\right)$ was compared to the original one-locus LOD scores $Z^{(1) o}\left(\tilde{\theta}^{\circ}\right)$, computed with agedependent penetrances and taking into account the uncertainty of diagnosis by increasing the phenocopy rate in liability classes corresponding to 'probable' or 'possible' diagnoses [40, pp 151-170]. Given that $Z^{(1) o}\left(\tilde{\theta}^{\circ}\right)$ was only maximized over the mode of inheritance and two analysis types (one considering affected and unaffected subjects and another considering only affected subjects), we applied a penalty $d=0.8$ to $Z\left(\breve{\theta}_{1}, 1 / 2, \breve{k}\right)$, because shifting the null distribution of $Z\left(\breve{\theta}_{1}, 1 / 2, \breve{k}\right)$ to the left by 0.8 insured that it dominated the null distribution of $Z^{(1) o}\left(\tilde{\theta}^{\circ}\right)$ in our simulations, i.e. that $Z\left(\breve{\theta}_{1}, 1 / 2, \breve{k}\right)$ had higher statistical significance. We used LOD scores instead of HLOD scores at Step 1 based on the results of our simulations. After Step 1, we prioritized marker pairs for two-locus two-marker analysis among the 56 pairs formed with the markers selected at Step 1 by ranking them in decreasing order of Spearman correlation of individual family LOD scores (the highest among $Z^{(1) o}$ and $Z\left(\theta_{1}, 1 / 2\right)$ ), maximized with respect to $\theta_{1}$ separately in each family [15].

Simulations under the null hypothesis were performed using the actual structure of 38 pedigrees on which computations were consistently successful. For the tested marker, we simulated genotypes from a marker with four equifrequent alleles unlinked to any disease locus using the program Simulate [41], and for the conditioning marker we used the actual genotypes from two markers among those with the highest $Z\left(\breve{\theta}_{1}, 1 / 2, \breve{k}\right.$ ) (SCA1 for BP and D13S1272 for SZ). The heavy computational burden in our large pedigrees limited the number of replicates to 5,000 , and two-locus two-marker computations were only performed on the replicates satisfying the Step 1 criteria. We then extrapolated extreme quantiles of the dis- 
Table 4. Conditional linkage signals under epistatic models in schizophrenia and bipolar disorder families from Eastern Quebec with and without selection of families linked to the conditioning marker

\begin{tabular}{|c|c|c|c|c|c|c|c|c|c|c|c|c|c|c|c|c|}
\hline \multirow{2}{*}{$\begin{array}{l}\text { Condition- } \\
\text { ing marker }\end{array}$} & \multirow{2}{*}{$\begin{array}{l}\text { Tested } \\
\text { marker }\end{array}$} & \multirow[t]{2}{*}{ Pheno $^{\mathrm{a}}$} & \multicolumn{9}{|c|}{ All families } & \multicolumn{5}{|c|}{ Selected families } \\
\hline & & & $\mathrm{n}^{\mathrm{b}}$ & $\operatorname{corr}^{\mathrm{c}}$ & $\begin{array}{l}\mathrm{Z} \\
\left(\hat{\theta}_{1}, \hat{\theta}_{2}\right)\end{array}$ & $\mathrm{Z}^{\mathrm{C} 1}$ & $\mathrm{p}^{\mathrm{e}}$ & $Z^{(2) o d}$ & $\mathrm{p}$ & $Z^{(2)}$ & $\mathrm{p}$ & $\mathrm{n}^{+\mathrm{f}}$ & $\mathrm{Z}^{\mathrm{C} 1+}$ & $\mathrm{p}^{\mathrm{e}}$ & $Z^{(2) C 1+}$ & $\mathrm{p}^{\mathrm{e}}$ \\
\hline D18S1145 & IGF1 (12q) & $\mathrm{BPb}$ & 34 & 0.50 & 3.69 & 1.21 & 0.07 & $1.66^{\mathrm{g}}$ & 0.01 & 1.40 & 0.03 & 21 & 2.08 & 0.006 & 2.22 & 0.007 \\
\hline D16S499 & D8S2317 & $\mathrm{BPn}$ & 26 & 0.43 & 2.94 & 2.00 & 0.04 & $1.93^{\mathrm{g}}$ & 0.006 & 2.20 & 0.003 & 13 & 3.44 & 0.0004 & 3.75 & 0.0008 \\
\hline D15S122 & D18S1145 & $\mathrm{BPb}$ & 34 & 0.40 & 2.68 & 2.42 & 0.004 & 3.09 & 0.0003 & 3.06 & 0.0003 & 15 & 4.92 & $<0.0001$ & 4.54 & $<0.0001$ \\
\hline D8S2317 & D16S683 & $\mathrm{BPn}$ & 26 & 0.31 & 3.51 & 1.48 & 0.08 & $0.95^{\mathrm{g}}$ & 0.07 & 1.37 & 0.03 & 15 & 2.28 & 0.009 & 1.33 & 0.2 \\
\hline D16S683 & D15S122 & $\mathrm{BPn}$ & 26 & 0.31 & 2.32 & 1.41 & 0.2 & 0.35 & 0.4 & 1.31 & 0.03 & 15 & 2.63 & 0.005 & 1.98 & 0.05 \\
\hline D16S410 & D15S122 & $\mathrm{BPn}$ & 26 & 0.29 & 1.95 & 1.43 & 0.1 & 0.35 & 0.4 & 1.31 & 0.03 & 14 & 3.44 & 0.0004 & 2.88 & 0.006 \\
\hline D13S1491 & D18S472 & $\mathrm{SZn}$ & 31 & 0.25 & 2.30 & 1.61 & 0.09 & 1.40 & 0.02 & 2.52 & 0.001 & 16 & 2.62 & 0.005 & 2.49 & 0.01 \\
\hline IGF1(12q) & D15S122 & $\mathrm{BPb}$ & 34 & 0.21 & 3.20 & 2.51 & 0.003 & 0.0 & 1.0 & 2.44 & 0.002 & 16 & 1.76 & 0.02 & 2.43 & 0.004 \\
\hline $\begin{array}{r}\text { a 'BP' an } \\
\text { disorder is c } \\
\text { b Numbe } \\
{ }^{c} \text { Spearm } \\
{ }^{\mathrm{d}} \text { One-lo } \\
\text { e p value } \\
\text { phenotype a } \\
{ }^{\mathrm{f}} \text { Numbe } \\
\text { g LOD sc }\end{array}$ & $\begin{array}{l}\text { d 'SZ' stand f } \\
\text { onsidered. } \\
\text { r of informat } \\
\text { lan correlatio } \\
\text { cus LOD scor } \\
\text { s for conditio } \\
\text { nd outside th } \\
\text { r of informat } \\
\text { ore from an }\end{array}$ & $\begin{array}{l}\text { r 'bipolar } \\
\text { ve familie } \\
\text { between } \\
\text { under th } \\
\text { al LOD } \\
\text { region o } \\
\text { e familie } \\
\text { fected-or }\end{array}$ & $\begin{array}{l}\text { es. } \\
\text { per- } \\
\text { he ori } \\
\text { score } \\
\text { f the } \\
\text { es wit } \\
\text { nly a }\end{array}$ & $\begin{array}{l}\text { amily o } \\
\text { sinal pe } \\
\text { have b } \\
\text { ested } \mathrm{m} \\
\mathrm{Z}_{\mathrm{i}}\left(\breve{\theta}_{1},(\right. \\
\text { alysis. }\end{array}$ & $\begin{array}{l}\text { e-locus } \\
\text { etrance } \\
\text { en mult } \\
\text { rker) to } \\
, 1 / 2, \mathrm{k})\end{array}$ & $\begin{array}{l}\text { CD s } \\
\text { model } \\
\text { plied } \\
\text { contrc } \\
0 .\end{array}$ & $\begin{array}{l}\text { res for } \\
\text { epend } \\
\text { the } n \\
\text { he Ty }\end{array}$ & $\begin{array}{l}\text { he two r } \\
t \text { of age } \\
\text { aber of } \\
\text { I error. }\end{array}$ & $\begin{array}{l}\text { arkers. } \\
\text { nd diag } \\
\text { larkers }\end{array}$ & $\begin{array}{l}\text { nosis } \\
\text { select }\end{array}$ & $\begin{array}{l}\text { tainty. } \\
\text { at Step }\end{array}$ & lat co & ald be & sed for co & aditionir & $\begin{array}{l}\text { on of the } \\
\text { ng (same }\end{array}$ \\
\hline
\end{tabular}

tribution in our actual family sample using the distributions of $\mathrm{Z}^{\mathrm{Cl}}$ and $\mathrm{Z}^{\mathrm{Cl}+}$ estimated in the small families from our simulation study based on a linear regression between the quantiles of the distributions in the two samples over the range 0.99 to 0.999 .

\section{Results}

The application of the Step 1 criteria selected 18 markers among 68 over the seven regions. Results for the eight marker pairs with LOD score correlation above 0.2 are presented in table 4 . Both markers in each pair were tested conditional on the other, and in table 4 the markers labelled as tested markers are those showing the greatest improvement in signal from applying Step 3. The sliced and conditional LOD scores being similar, we present only conditional LODs. The Step 2 statistic $\mathrm{Z}^{\mathrm{C} 1}$ did not improve the statistical significance of linkage to any marker, after Bonferroni correction for conditioning on multiple loci, compared to one-locus LOD scores under the original penetrance models or with maximization over one-locus models. In contrast, the Step 3 statistics $\mathrm{Z}^{\mathrm{Cl} 1+}$ and $\mathrm{Z}^{(2) \mathrm{Cl} 1+}$ were both more significant than the onelocus LOD scores for most markers. The three strongest signals exceed the usual genomewide threshold for suggestive linkage: for the broad BP phenotype: $\mathrm{D} 18 \mathrm{~S} 1145$ (18q13) conditioned on D15S122 $\left(\mathrm{Z}^{\mathrm{Cl}+}=4.92\right.$ at $\theta=0.10$, $\mathrm{p}<0.0001)$ and for the narrow BP phenotype: D8S2317 (8p11) conditioned on D16S499 $\left(\mathrm{Z}^{\mathrm{Cl}+}=3.44\right.$ at $\theta=0.10$, $\mathrm{p}=0.0004)$ and D15S122 (15q11) conditioned on D16S410 $\left(\mathrm{Z}^{\mathrm{C} 1+}=3.44\right.$ at $\left.\theta=0.05, \mathrm{p}=0.0004\right)$. D18S1145 had the highest one-locus LOD scores in the 18q12-q21 region in the initial sample [19].

\section{Discussion}

We have proposed a complete three-step strategy for linkage analysis in presence of two-locus epistasis taking into account genetic heterogeneity. In Step 1, pre-screening loci likely to be involved in epistasis using a onemarker, two-locus analysis limits the number of marker pairs to test in computer intensive two-locus two-marker analyses. Conditioning on linkage evidence to one of the epistatic loci in Step 2 allows to select linked families in Step 3 without biasing the conditional LOD score for the other locus, providing a practical way to address heterogeneity. Maximization over a class of two-locus epistatic models avoids the need to specify penetrances and DS allele frequencies. The approach can be applied to markers genomewide to detect loci where the one-locus signal is weakened by epistasis and heterogeneity. The better fit provided by epistatic models makes markers linked to 
such loci likely to be selected at Step 1 . Testing the same markers conditional on a marker linked to an epistatic locus in Steps 2 and 3 should then reveal a strong signal. This is what we observed in our simulations under epistasis and heterogeneity in extended pedigrees with unaffected obligate carriers. The approach can also be applied to markers previously detected in one-locus analyses. In that case, we interpret signal improvements as evidence of epistasis, with or without heterogeneity. We found such evidence of epistasis in the application to SZ and BP kindreds.

Our simulation study showed the power advantage of our strategy over alternatives including applying the same family selection scheme with one-locus LOD scores (Cox et al.'s [27] approach) and applying Smith's mixture model to the conditional LOD score. Application of Cox et al.'s approach with NPL statistics as originally proposed was not undertaken, but since NPL statistics ignore information from unaffected subjects, power would likely be lower than that of our parametric version of Cox et al.'s approach.

In the conditioning on linkage to a locus 1 , we have distinguished $\mathrm{Z}^{\mathrm{S1}}$ and $\mathrm{Z}^{\mathrm{C} 1}$ based on the choice of value for $\theta_{1}$ in the log-likelihood under the null hypothesis: the value $\hat{\theta}_{1}(\mathrm{k})$ maximizing the two-locus two-marker LOD score or the value $\breve{\theta}_{1}(\mathrm{k})$ maximizing the two-locus onemarker LOD score. These two values of $\theta_{1}$ are usually close, and would be both equal to 0 in the case of tight linkage and perfect model fit. Small differences between the two can however matter when selecting linked families under our proposed treatment of heterogeneity. Individual family one-marker two-locus LOD scores are more often positive at $\breve{\theta}_{1}(\mathrm{k})$ than at $\hat{\theta}_{1}(\mathrm{k})$, leading to more families being selected. While this could have affected the power to detect locus 2 either way, our simulations indicated that selection at $\breve{\theta}_{1}(\mathrm{k})$ provides slightly higher power. We also tried various fractional family weighting schemes to capture the magnitude of the individual family LOD scores at locus 1 instead of simple $0-1$ weights, but none of our attempts outperformed the $0-1$ weights (results not shown).

In an affected-only analysis, the two-locus LOD score under a multiplicative model is the sum of the one-locus LOD scores at the two loci. This has led some authors [15, 26] to propose that one-locus models can be used to approximate a two-locus epistatic model, even in extended pedigrees with unaffected subjects, thereby eliminating the need for two-locus analysis. If this were true then the conditional and sliced LOD scores would provide little gain over one-locus LOD scores. Our results demonstrat- ed to the contrary that much power can be gained from a two-locus model in extended pedigrees when unaffected pedigree members contribute to the phenotypic data.

Our focus in this work on analyzing one highly polymorphic marker at each locus was motivated by the data from our study of SZ and BP: an $8 \mathrm{cM}$ genome scan with microsatellite markers [19]. In linkage studies using denser sets of less polymorphic single nucleotide polymorphisms (SNPs), multipoint analyses are needed to extract full inheritance information. Our strategy remains applicable in the multipoint context with a few adaptations. In Step 1, instead of preselecting individual markers, one could preselect chromosomal regions or full chromosomes. Subsequent steps would involve pairs of regions or chromosomes, and multipoint linkage statistics would be maximized over these regions instead of recombination fractions with single markers. Multipoint LOD scores not being usual LR statistics [42], null distributions should always be determined by simulation, even under a fixed genetic model. The multipoint context also presents additional computational difficulties: programs designed for optimal multi-point computations (Genehunter Twolocus [43]) impose severe limitations on pedigree size, while there is a trade-off between number of markers and pedigree size with Superlink.

The relevance of linkage analysis is being questioned in the age of genomewide association studies. However, there are many areas of genetic analysis where a strong case can be made that linkage analysis has a role to play [44], including the analysis of epistasis. The pattern of transmission of alleles to affected and unaffected relatives in extended pedigrees allows to trace epistatic effects between genes, and pedigrees have been used to highlight epistasis in humans [45]. Population-based cohort and case-control studies estimate penetrances directly, but only if the disease variant, or a marker in perfect linkage disequilibrium (LD) with it, is genotyped. Imperfect LD and large scale multiple testing lead to extremely high sample size requirements for studying epistatic effects [46]. Linkage studies of epistasis using strategies such as the one proposed in this paper, despite providing only crude gene localization, generate hypotheses of epistasis which can then be tested at the gene level with the higher resolution of association studies.

In our extended SZ and/or BP kindreds, summing the LOD scores for the tested marker of only the families with a positive LOD score at a conditioning marker revealed improvements in signal compared to using all families for the seven marker pairs with highest correlation of perfamily one-locus LOD scores. Such success with the treat- 
ment of heterogeneity may be explained by the observation that one-locus LOD scores are highly positively correlated when epistasis and heterogeneity are both present, but not when epistasis is present without heterogeneity [15]. Strong one-locus LOD score correlations may also explain the high $\mathrm{Z}^{(2) \mathrm{Cl} 1}$ observed for the most correlated marker pairs, despite the low power of $\mathrm{Z}^{(2) \mathrm{Cl}+}$ in our simulations. The improvements in linkage signal for BP detected on 8 p11 and $15 \mathrm{q} 11$ conditional on 16p13, with the latter showing a strong one-locus linkage to $\mathrm{BP}$ in our sample [20], and on 18q12 conditional on 15q11 suggest epistasis between genes at these loci in subsets of families. It is noteworthy that $18 \mathrm{q} 12-\mathrm{q} 21$ was a region where the one-locus LOD score showed up as lower in the full kindred sample (table 4) than in our initial sample [19]. To the contrary, $\mathrm{Z}^{\mathrm{Cl}+}$ was higher in the expanded sample (4.92) than in the initial sample (2.39), highlighting that modelling epistasis and heterogeneity might help to replicate linkage signals.

Our simulation study revealed that our proposed strategy increases linkage signals at loci where the one-locus signal is weak because of epistasis and heterogeneity. Application to SZ and BP kindreds succeeded in improving linkage signals within previously detected regions, suggesting the presence of epistasis. These results support the claim that our strategy is powerful to detect loci with little marginal effect and to detect epistatic effects between loci for complex phenotypes involving epistasis and heterogeneity.

\section{Acknowledgements}

This work was supported by the Canadian Institutes of Health Research (grants IPG-77885 and MT-12854), and by a Canada Research Chair (\# 950-200810) in the genetics of neuropsychiatric disorders of which M. Maziade is the Chair. A. Bureau is supported by a research fellowship from the Fonds de recherche en santé du Québec. We thank Nathalie Savard for performing part of the Perl and R programming and Claudia Émond for her input on two-locus analyses and computation of LOD score correlations.

\section{References}

1 Cordell HJ: Epistasis: what it means, what it doesn't mean, and statistical methods to detect it in humans. Hum Mol Genet 2002;11: 2463-2468.

$\checkmark 2$ Moore JH: The ubiquitous nature of epistasis in determining susceptibility to common human diseases. Hum Hered 2003;56:7382.

-3 Risch N: Linkage strategies for genetically complex traits. I. Multilocus models. Am J Hum Genet 1990;46:222-228.

$\checkmark 4$ Vieland VJ, Huang J: Two-locus heterogeneity cannot be distinguished from two-locus epistasis on the basis of affected-sib-pair data. Am J Hum Genet 2003;73:223-232.

$\checkmark 5$ Strauch K, Fimmers R, Baur MP, Wienker TF: How to model a complex trait. 2. Analysis with two disease loci. Hum Hered 2003; 56:200-211

-6 Cordell HJ, Todd JA, Bennett ST, Kawaguchi Y, Farrall M: Two-locus maximum lod score analysis of a multifactorial trait: joint consideration of IDDM2 and IDDM4 with IDDM1 in type 1 diabetes. Am J Hum Genet 1995;57:920-934

-7 Cordell HJ, Wedig GC, Jacobs KB, Elston RC: Multilocus linkage tests based on affected relative pairs. Am J Hum Genet 2000;66: 1273-1286.

$\checkmark 8$ Liang KY, Chiu YF, Beaty TH, Wjst M: Multipoint analysis using affected sib pairs: incorporating linkage evidence from unlinked regions. Genet Epidemiol 2001;21:105-122.
-9 Farrall M: Affected sibpair linkage tests for multiple linked susceptibility genes. Genet Epidemiol 1997;14:103-115.

10 Holmans P: Detecting gene-gene interac tions using affected sib pair analysis with covariates. Hum Hered 2002;53:92-102.

11 Schaid DJ, McDonnell SK, Carlson EE, Thibodeau SN, Ostrander EA, Stanford JL: Affected relative pairs and simultaneous search for two-locus linkage in the presence of epistasis. Genet Epidemiol 2007;31:431449.

12 Hallgrimsdottir IB, Speed TP: The power of two-locus affected sib-pair linkage analysis to detect interacting disease loci. Genet Epidemiol 2008;32:84-88.

13 Schork NJ, Boehnke M, Terwilliger JD, Ott J: Two-trait-locus linkage analysis: a powerful strategy for mapping complex genetic traits. Am J Hum Genet 1993;53:1127-1136.

14 Tienari PJ, Terwilliger JD, Ott J, Palo J, Peltonen L: Two-locus linkage analysis in multiple sclerosis (MS). Genomics 1994;19:320325.

15 MacLean CJ, Sham PC, Kendler KS: Joint linkage of multiple loci for a complex disorder. Am J Hum Genet 1993;53:353-366.

16 Smith CA: Testing for Heterogeneity of Recombination Fraction Values in Human Genetics. Ann Hum Genet 1963;27:175-182.

17 Greenberg DA: Inferring mode of inheritance by comparison of lod scores. Am J Med Genet 1989;34:480-486.
18 Yoo YJ, Mendell NR: The power and robustness of maximum LOD score statistics. Ann Hum Genet 2008;72:566-574.

19 Maziade M, Roy MA, Chagnon YC, Cliche D, Fournier JP, Montgrain N, Dion C, Lavallee JC, Garneau Y, Gingras N, Nicole L, Pires A, Ponton AM, Potvin A, Wallot H, Merette C: Shared and specific susceptibility loci for schizophrenia and bipolar disorder : A dense genome scan in Eastern Quebec families. Mol Psychiatry 2005;10:486-499.

20 Merette C, Roy MA, Bureau A, Fournier A, Emond C, Cliche D, Jomphe V, Chagnon YC, Maziade M: Replication of linkage with bipolar disorder on chromosome $16 \mathrm{p}$ in the eastern Quebec population. Am J Med Genet B Neuropsychiatr Genet 2008;147B:737744.

21 Vieland V, Greenberg DA, Hodge SE, Ott J: Linkage analysis of two-locus diseases under single-locus and two-locus analysis models. Cytogenet Cell Genet 1992;59:145-146.

$\checkmark 22$ Dupuis J, Brown PO, Siegmund D: Statistical methods for linkage analysis of complex traits from high-resolution maps of identity by descent. Genetics 1995;140:843-856.

-23 Sung YJ, Thompson EA, Wijsman EM: MCMC-based linkage analysis for complex traits on general pedigrees: multipoint analysis with a two-locus model and a polygenic component. Genet Epidemiol 2007;31:103114. 
24 Sung YJ, Wijsman EM: Accounting for epistasis in linkage analysis of general pedigrees. Hum Hered 2007;63:144-152.

25 Serfling RJ: Approximation Theorems of Mathematical Statistics. New York, Wiley, 1980.

26 Terwilliger JD: A likelihood-based extended admixture model of oligogenic inheritance in 'model-based' and 'model-free' analysis. Eur J Hum Genet 2000;8:399-406.

$\checkmark 27$ Cox NJ, Frigge M, Nicolae DL, Concannon P, Hanis CL, Bell GI, Kong A: Loci on chromosomes 2 (NIDDM1) and 15 interact to increase susceptibility to diabetes in Mexican Americans. Nat Genet 1999;21:213-215.

28 Kong A, Cox NJ: Allele-sharing models: LOD scores and accurate linkage tests. Am J Hum Genet 1997;61:1179-1188.

-29 Kruglyak L, Daly MJ, Reeve-Daly MP, Lander ES: Parametric and nonparametric linkage analysis: a unified multipoint approach. Am J Hum Genet 1996;58:1347-1363.

-30 Mattheisen M, Dietter J, Knapp M, Baur MP, Strauch K: Inferential testing for linkage with GENEHUNTER-MODSCORE: the impact of the pedigree structure on the null distribution of multipoint MOD scores. Genet Epidemiol 2008;32:73-83.

- 31 Fishelson M, Geiger D: Exact genetic linkage computations for general pedigrees. Bioinformatics 2002;18(suppl 1):S189-198.

- 32 Fishelson M, Geiger D: Optimizing exact genetic linkage computations. J Comput Biol 2004;11:263-275.

33 Schmidt M, Hauser ER, Martin ER, Schmidt S: Extension of the SIMLA package for generating pedigrees with complex inheritance patterns: environmental covariates, genegene and gene-environment interaction. Stat Appl Genet Mol Biol 2005;4:Article15.

-34 Lander E, Kruglyak L: Genetic dissection of complex traits: guidelines for interpreting and reporting linkage results. Nat Genet 1995;11:241-247.
35 Chiu YF, McGrath JA, Thornquist $\mathrm{MH}$, Wolyniec PS, Nestadt G, Swartz KL, Lasseter VK, Liang KY, Pulver AE: Genetic heterogeneity in schizophrenia II: conditional analyses of affected schizophrenia sibling pairs provide evidence for an interaction between markers on chromosome $8 \mathrm{p}$ and $14 \mathrm{q}$. Mo Psychiatry 2002;7:658-664.

36 Abou Jamra R, Fuerst R, Kaneva R, Orozco Diaz G, Rivas F, Mayoral F, Gay E, Sans S, Gonzalez MJ, Gil S, Cabaleiro F, Del Rio F, Perez F, Haro J, Auburger G, Milanova V, Kostov C, Chorbov V, Stoyanova V, Nikolova-Hill A, Onchev G, Kremensky I, Jablensky A, Schulze TG, Propping P, Rietschel M, Nothen MM, Cichon S, Wienker TF, Schumacher J: The first genomewide interaction and locus-heterogeneity linkage scan in bipolar affective disorder: strong evidence of epistatic effects between loci on chromosomes 2q and 6q. Am J Hum Genet 2007;81 974-986.

37 Maziade M, Raymond V, Cliche D, Fournier JP, Caron C, Garneau Y, Nicole L, Marcotte P, Couture C, Simard C, Boivin R, Rodrigue C, Boutin P, De Braekeleer M, Martinez M, Mérette C: Linkage results on 11q21-22 in Eastern Quebec pedigrees densely affected by schizophrenia. Am J Med Genet 1995;60 522-528.

>38 Maziade M, Roy M-A, Fournier J-P, Cliche D, Mérette C, Caron C, Garneau Y, Montgrain N, Shriqui C, Dion C, Nicole L, Potvin A, Lavallée J-C, Pirès A, Raymond V: Reliability of best-estimate diagnosis in genetic linkage studies of major psychoses : results from the Québec pedigree studies. Am J Psychiatry 1992;149:1674-1686.
39 Roy MA, Lanctôt G, Mérette C, Cliche D, Fournier J-P, Boutin P, Rodrigue C, Charron L, Turgeon M, Hamel M, Montgrain N, Nicole L, Pirès A, Wallot H, Ponton AM, Garneau Y, Dion C, Lavallée JC, Potvin A, Szatmari P, Maziade M: Clinical and methodological factors related to reliability of the best-estimate diagnostic procedure. Am J Psychiatry 1997;154:1726-1733.

40 Ott J: Analysis of Human Genetic Linkage, ed 3. Baltimore, Johns Hopkins University Press, 1999.

41 Terwilliger JD, Speer M, Ott J: Chromosome-based method for rapid computer simulation in human genetic linkage analysis. Genet Epidemiol 1993;10:217-224.

-42 Hodge SE, Rodriguez-Murillo L, Strug LJ, Greenberg DA: Multipoint lods provide reliable linkage evidence despite unknown limiting distribution: type I error probabilities decrease with sample size for multipoint lods and mods. Genet Epidemiol 2008;32:800815.

43 Dietter J, Spiegel A, an Mey D, Pflug HJ, AlKateb H, Hoffmann K, Wienker TF, Strauch $\mathrm{K}$ : Efficient two-trait-locus linkage analysis through program optimization and parallelization: application to hypercholesterolemia. Eur J Hum Genet 2004;12:542-550.

$>44$ Clerget-Darpoux F, Elston RC: Are linkage analysis and the collection of family data dead? Prospects for family studies in the age of genome-wide association. Hum Hered 2007;64:91-96.

$\checkmark 4$ Badano JL, Leitch CC, Ansley SJ, MaySimera H, Lawson S, Lewis RA, Beales PL, Dietz HC, Fisher S, Katsanis N: Dissection of epistasis in oligogenic Bardet-Biedl syndrome. Nature 2006;439:326-330.

$\checkmark 46$ Burton PR, Hansell AL, Fortier I, Manolio TA, Khoury MJ, Little J, Elliott P: Size matters: just how big is BIG?: Quantifying realistic sample size requirements for human genome epidemiology. Int J Epidemiol 2009;38: 263-273. 